\title{
Do provider birth attitudes influence cesarean delivery rate: a cross-sectional study
}

\author{
Emily White VanGompel ${ }^{1,2^{*}}$ D, Elliott K. Main ${ }^{3}$, Daniel Tancredi ${ }^{4}$ and Joy Melnikow ${ }^{5}$
}

\begin{abstract}
Background: When used judiciously, cesarean sections can save lives; but in the United States, prior research indicates that cesarean birth rates have risen beyond the threshold to help women and infants and become a contributor to increased maternal mortality and rising healthcare costs. Healthy People 2020 has set the goal for nulliparous, term, singleton, vertex (NTSV) cesarean birth rate at no more than $23.9 \%$ of births. Currently, cesarean rates vary from $6 \%$ to $69 \%$ in US hospitals, unexplained by clinical or demographic factors. This wide variation in cesarean use is also seen among individual providers of intrapartum care. Previous research of birth attitudes found providers of intrapartum care hold widely differing views, which may be a key underlying factor influencing practice variation; however, further study is needed to determine if differences in attitudes are associated with differences in clinical outcomes. The purpose of this study was to estimate the association between individual provider attitudes towards birth and their low-risk primary cesarean rate.

Methods: Four hundred providers were drawn from a stratified random sample of all California providers of intrapartum care in 2013 and surveyed for their attitudes towards various aspects of labor and birth. Providers' NTSV cesarean birth rates were obtained for 2013 and 2014. Covariates included gender, years of experience, practice location, and primary hospital's NTSV cesarean rate. We used adjusted multivariate Poisson regression to compare cesarean rates and linear regression to compare attitude scores of providers meeting versus not meeting the Healthy People 2020 (HP2020) goal.

Results: Two hundred nine total participants (obstetricians, family physicians, and midwives) completed surveys, of which 109 perform cesareans. Providers' NTSV cesarean rate was significantly associated with their composite attitudes score [IRR for each one-point increase 1.21 (95\% Cl 1.002-1.45)]. Physicians meeting the HP2020 goal held attitudes which were significantly more favorable towards vaginal birth: mean 2.70 ( $95 \% \mathrm{Cl} 2.58-2.83$ ) versus 2.91 (95\% Cl 2.82-3.00), $p<0.01$.

Conclusions: Provider attitudinal differences are associated with NTSV cesarean rates. Those meeting the HP2020 goal hold attitudes more favorable towards vaginal birth. These findings may present a modifiable target for quality improvement initiatives to decrease low risk primary cesareans.
\end{abstract}

Keywords: Cesarean section, Provider attitudes, Quality improvement, Primary cesarean, Culture

\footnotetext{
* Correspondence: EWhiteVanGompel@northshore.org

'Department of Family Medicine, The University of Chicago, Pritzker School

of Medicine, NorthShore University HealthSystem Research Institute, 1001

University Place, Evanston, IL 60201, USA

${ }^{2}$ Department of Obstetrics and Gynecology, The University of Chicago,

Pritzker School of Medicine, NorthShore University HealthSystem Research

Institute, 1001 University Place, Evanston, IL 60201, USA

Full list of author information is available at the end of the article
}

(c) The Author(s). 2018 Open Access This article is distributed under the terms of the Creative Commons Attribution 4.0 International License (http://creativecommons.org/licenses/by/4.0/), which permits unrestricted use, distribution, and reproduction in any medium, provided you give appropriate credit to the original author(s) and the source, provide a link to the Creative Commons license, and indicate if changes were made. The Creative Commons Public Domain Dedication waiver (http://creativecommons.org/publicdomain/zero/1.0/) applies to the data made available in this article, unless otherwise stated. 


\section{Background}

Cesarean sections, when used judiciously, save lives; however, research indicates that the use of cesareans in the United States has risen well above the level of necessity and has become a contributor to maternal morbidity and mortality [1-5]. Women who are nulliparous, at full term, with a singleton pregnancy in vertex presentation (NTSV) have been established as a standard population and used as a target group for reducing the cesarean birth rate [6-8]. Healthy People 2020 has set the goal for NTSV cesarean rate at no more than $23.9 \%$ of births [6]. Currently, cesarean rates vary from $6 \%$ to $69 \%$ in US hospitals [9]. Substantial variation persists after adjustment for hospital demographics, referral categories, or teaching status, and after adjustment for patient clinical or sociodemographic factors $[9,10]$.

Wide variation is also seen between providers, even those practicing within the same hospital and utilizing a laborist model [11]. Over $90 \%$ of the variation in the NTSV cesarean rate is due to two indications: "fetal intolerance of labor" and "failure to progress"; indications requiring subjective decision-making by the intrapartum provider [12]. The American Congress of Obstetricians and Gynecologists' Committee Opinion on limiting intervention during labor highlights the labor management techniques that, despite prevailing evidence, vary significantly among providers [13]. Evidence is filtered through the lens of a provider's experiences and attitudes [14]; yet how these attitudes affect clinical outcomes has not been evaluated.

Previous research found differences in birth attitudes between providers of different disciplines (obstetrics, family medicine, midwifery) $[15,16]$; yet did not examine clinical outcomes. The objective of this study was to examine the association of individual provider NTSV cesarean rates with their attitudes towards birth. In contrast to earlier studies examining physician demographic factors [17-19], this study sought to evaluate a potentially modifiable personal attribute that may contribute to cesarean overuse.

\section{Aim}

Our primary aim was to assess the association between providers' birth attitudes and their NTSV cesarean rates.

\section{Methods}

\section{Design}

A stratified random sample of providers listed as delivering clinicians on California birth certificates in 2013 were surveyed with a previously validated survey instrument of provider birth attitudes [16]. We linked providers' scores on this survey with their individual NTSV cesarean rates for the years of 2013 and 2014, as calculated by the California Maternal Data Center (CMDC), a service of the California Maternal Quality Care Collaborative. Baseline demographics and survey scores were analyzed using SAS Version 9.4. Poisson regressions were performed using Stata 12.1. This study was approved under expedited review by University of California Davis Internal Review Board. Participants received the consent document, but signed consent was waived by the IRB.

\section{Setting}

California has approximately 3500 providers that are listed as delivering clinicians in a given year; these include obstetricians (OB), Maternal-Fetal Medicine specialists, family medicine physicians, Certified Nurse Midwives (CNM), and California Licensed Midwives (LM). Practice settings are diverse, and include rural, urban, and frontier geographic locations, teaching hospitals, community hospitals, and tertiary care centers. Provider mix at each hospital may include only obstetricians or family physicians, or may include Maternal-Fetal Medicine specialists or midwives. The CMDC combines existing datasets, including monthly discharge and clinical data, birth certificate data, and semi-annual patient discharge data from the California Office of Statewide Health Planning and Development, to create hospital and physician-level quality improvement metrics. We obtained a stratified random sample from 2013 - the latest available year of complete data. At the time of final data collection, 2014 complete data became available, thus we included provider and hospital metrics from both 2013 and 2014 combined. Our primary sample size consideration was based on the six domain scores' ability to account for variation in NTSV cesarean delivery rate. Using pilot data, we determined that a sample size of 116 patients would provide $80 \%$ power to detect an $11.1 \%$ partial R-square. To account for intermittent missing variables, we targeted a sample of 130 survey participants.

Inclusion criteria for providers were: having been listed on a birth certificate as the delivering clinician in the year 2013, belonging to one of the key study disciplines (maternal-fetal medicine, OB, family medicine, CNM, LM), and having performed at least 10 deliveries per year. Providers with a license address outside the state of California and those without an identifiable discipline based either on license number prefix or NPI taxonomy code were excluded from sampling.

Based on prior research pointing to important influences on provider practice [17-19], stratification was performed based on three variables: provider discipline (maternal-fetal medicine, OB, family medicine, CNM, LM), geographic location as defined by the federally designated Medical Service Study Areas (rural = population density $<250$ persons/square mile; frontier = population density $<11$ persons/square mile; urban = anything not rural or frontier) [20], and years in practice $(<5$ years, 
5-15 years, $16-25$ years, $>25$ years). The stratified random sample was drawn in two rounds of 200 , for a total of 400 sampled providers. To ensure adequate power for analysis, oversampling was performed on provider groups other than obstetricians (who perform the vast majority of all births in California). Researchers were blinded to individual providers' cesarean rates during sample selection.

\section{Attitudes survey}

The birth attitudes survey, previously validated by Klein and colleagues, included 9 different domains assessing provider attitudes towards different aspects of labor and birth [16]. Six of these domains, comprising 31 Likert-style items, were chosen as those most likely to have an effect on the targeted outcome - low-risk primary cesareans. They included (renumbered for this study): Domain 1: attitudes regarding use of electronic fetal monitoring (Cronbach alpha $[\alpha]=0.704)$, Domain 2: factors that increase cesarean rates $(\alpha=0.810)$, Domain 3: fears of birth mode by respondents or their partners/spouses $(\alpha=0.929)$, Domain 4 : factors that decrease cesarean rates $(\alpha=0.819)$, Domain 5: maternal choice and mothers' roles in birth $(\alpha=0.646)$, and Domain 6 : safety by mode or place of birth $(\alpha=0.748)$. The composite scale combined the individual domain scores. Coding of domains 4 and 5 was reversed for directional consistency to create a total mean score. Lower scores on the composite scale indicate attitudes more favorable toward vaginal birth, while higher scores indicate attitudes that favor cesarean birth. Providers were also asked to give their discipline and years of experience. Each provider was assigned a random identifier, so that survey responses were not associated with provider name.

We used best practices for achieving maximal survey response as detailed by Dillman et al. [21] Survey data collection began in October 2015 and ended in April 2016. We sent the attitudes survey via postal mail and included a web address for optional completion online. The initial mailing included the 4-page survey, a cover letter, informed consent document, a self-addressed stamped envelope, and an incentive of a $\$ 10$ Starbucks gift card. Providers could opt to provide their email addresses to be entered into a drawing at the conclusion of the study for an iPad of approximately $\$ 400$ value at the conclusion of the study. One to two weeks after the initial mailing, we sent a postcard reminder to complete the survey. Between one and 2 months after the initial mailing, all non-responders were sent a second complete packet including cover letter, consent, survey document, and self-addressed stamped envelope.

\section{Provider-level cesarean rate}

The CMDC database uses the standard NQF-endorsed algorithm [4] to calculate the total number of births attended by a provider that qualify as primary low-risk cesareans. This criteria includes all nulliparous, term ( $>37$ weeks gestation), singleton gestations in vertex presentation at delivery. These are termed NTSV births for nulliparous, term, singleton, and vertex, and remain the primary target for quality improvement initiatives to decrease cesarean section overuse in the United States [6-8]. We obtained both the total number of NTSV births providers attended in 2013-2014, and the total number of those births that were delivered via cesarean from the CMDC database.

Not all providers included in the survey sample had privileges to perform cesareans. In order to provide a complete picture of the spectrum of attitudes held by all providers practicing as independent clinicians in California, we chose to include all those listed as delivering clinicians on at least 10 deliveries per study year. As it would not be appropriate to assess provider-level cesarean rates in providers who cannot perform cesareans, we excluded these providers from the NTSV predictive model. Both CNMs and LMs do not perform cesareans under any circumstances. A majority of family medicine physicians who do prenatal and intrapartum care do not perform cesareans; however, there are family medicine physicians who have done additional training to qualify to perform cesareans. There is no central database that tracks these privileges, thus this was ascertained by anonymously calling individual family medicine physicians' offices.

\section{Covariates}

Provider demographic data, including discipline (maternal-fetal medicine, Average Risk OB, family medicine, CNM, LM), gender, years since graduation from medical school ( $<5$ years, $5-15$ years, $16-25$ years, $>25$ years), practice geographic location (rural/urban), and hospitallevel demographics including hospital-level NTSV rate, neonatal intensive care unit level, and percent Medicaid were obtained from the CMDC database. Some providers practiced at multiple hospitals; however, the hospital where they had their greatest number of NTSV births was assigned as their primary hospital of delivery.

\section{Statistical methods}

Due to the large range of providers' total NTSV birth volume, we used multivariate Poisson regression to maximize precision of our estimation model, using counts of NTSV cesarean deliveries per provider as the dependent variable and total deliveries per provider as an "exposure" variable whose log-transformed value is included as an offset term, to account for between-provider variation. We used robust standard error estimators to protect against model misspecification. Simple regression with predicted margins was used to compare attitudinal scores between discipline groups. Attitude domain and composite means were calculated from all non-missing items. For the dichotomous 
Healthy People 2020 provider comparison, we compared providers' attitudes based on whether or not their NTSV cesarean rates met the Healthy People 2020 (HP2020) goal of less than $23.9 \%$ [6]. We used multiple linear regression, adjusting for provider gender, practice geography, and experience level to compare predicted means for each group. In order to adjust for the provider's hospital cultural environment, we adjusted each regression model for the primary hospital's NTSV rate exclusive of provider's contribution to this rate.

\section{Results}

We received 209 completed surveys, a total response rate of 52.3\%, including 22 maternal-fetal medicine, $101 \mathrm{OB}, 53$ family medicine, $16 \mathrm{CNM}$, and $17 \mathrm{LM}$ responding. There was a higher response rate for midwives, $97 \%$ of who were female, but no difference in disciplinary distribution or gender of physician respondents versus non-respondents. Experience level, practice geographic location, and primary hospital nursery level did not vary between respondents versus non-respondents. Respondents' primary hospitals had higher annual birth volumes than non-respondents' hospitals (mean $=5,203.9$ versus $2,666.8, p<0.001$ ). Hospital NTSV rates were slightly lower for respondents compared with non-respondents $(25.3 \%$ versus $26.8 \%, p<0.01)$. (Table 1).

Attitudes varied significantly according to provider discipline (Fig. 1). Each domain displayed a spectrum of provider attitudes towards birth, with midwives on one end of the spectrum and OBs on the other (Fig. 2). Family medicine physicians either fell between the two or held attitudes more similar to midwives. Maternal-fetal medicine physicians held attitudes most consistent with average risk OBs, but tended to express attitudes that fell between average risk OBs and family medicine physicians. The OB group had widest variation in composite attitude scores (range $=1.37$ to 4.33 ).

Of the 53 responding family medicine physicians, only 8 had privileges to perform cesareans, though 22 had "first assist" privileges. Family medicine physicians with cesarean privileges (family medicine-CS) were identical to family medicine physicians without privileges on the

Table 1 Demographic and Practice Characteristics of Responders and Non-responders

\begin{tabular}{|c|c|c|c|c|c|}
\hline & Responders (n) & Percent & Non-Responders (n) & Percent & $p$-value \\
\hline N & 209 & & 191 & & \\
\hline Discipline & & & & & $0.35^{a}$ \\
\hline MFM & 22 & 10.5 & 19 & 9.9 & \\
\hline $\mathrm{OB}$ & 101 & 48.3 & 120 & 62.8 & \\
\hline Family Medicine & 53 & 25.4 & 46 & 24.1 & \\
\hline CNM & 16 & 7.7 & 3 & 2.1 & \\
\hline LM & 17 & 8.1 & 3 & 1.6 & \\
\hline Gender & & & & & $0.29^{a}$ \\
\hline Female & 132 & 63.2 & 102 & 53.4 & \\
\hline Male & 77 & 36.8 & 89 & 46.6 & \\
\hline Experience & & & & & 0.49 \\
\hline$<5$ years & 35 & 18.3 & 28 & 13.9 & \\
\hline $5-15$ years & 58 & 30.4 & 70 & 34.7 & \\
\hline $16-25$ years & 46 & 24.1 & 43 & 21.3 & \\
\hline$>25$ years & 52 & 27.2 & 61 & 30.2 & \\
\hline Hospital NICU Level & & & & & 0.64 \\
\hline Basic Nursery & 50 & 23.9 & 57 & 29.8 & \\
\hline Community Nursery & 82 & 39.2 & 73 & 38.2 & \\
\hline Intermediate Nursery & 36 & 17.2 & 33 & 17.3 & \\
\hline Regional Nursery & 20 & 9.6 & 25 & 13.1 & \\
\hline Continuous Variables & Mean & SD & Mean & SD & $p$-value \\
\hline Hospital Birth Volume ${ }^{b}$ & 5203.9 & 3835.9 & 2666.8 & 2012.8 & $<0.0001$ \\
\hline Hospital NTSV CS Rate & 25.30 & 4.80 & 26.80 & 6.10 & $<0.01$ \\
\hline
\end{tabular}

Abbreviations: MFM maternal fetal medicine, $O B$ obstetricians, Family Medicine family medicine physicians, CNM certified nurse midwives, $L M$ licensed midwives, NICU neonatal intensive care unit, NTSV CS nulliparous, term, singleton, vertex cesarean section

${ }^{a} P$-value includes physicians only. Midwives were all female except for one participant and had exceptionally high response rate

${ }^{\mathrm{b}}$ Calculated for provider's primary delivering hospital site 


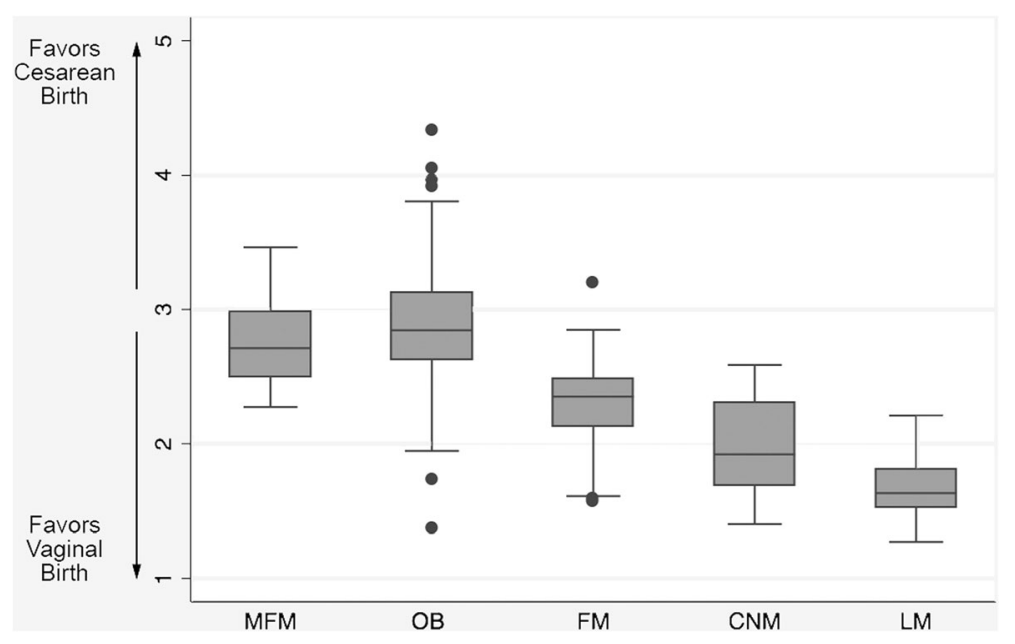

Fig. 1 Mean Provider Attitudes Scores on the Composite Scale by Provider Discipline. Figure 1 is a boxplot of providers' mean attitude scores on the composite attitudes scale categorized by provider membership in a training discipline. Abbreviations: MFM: maternal fetal medicine; OB: obstetricians; family medicine: family medicine physicians; CNM: certified nurse midwives; LM: licensed midwives

composite scale (mean 2.31 with SD 0.16 , and 2.31 with SD 0.35, respectively, $p=0.98$ ). For the most part, family medicine-CS physicians expressed attitudes on the individual domains that were slightly less favorable towards vaginal delivery than family medicine physicians; however, family medicine-CS tended to endorse less fear of vaginal delivery than their family medicine counterparts, though this was not statistically significant (mean $1.19 \pm 0.30$ versus $1.40 \pm 0.74$, respectively, $p=0.43$ ). The database attributed cesarean deliveries to 14 family medicine physicians without any cesarean privileges and 10 family medicine physicians with first assist privileges.

The analyses of association of provider attitudes with NTSV cesarean rates included only providers with cesarean privileges and at least 20 NTSV deliveries within the 2 year study period: 11 maternal-fetal medicine, $91 \mathrm{OB}$, and 7 family medicine physicians. The composite attitudes scale scores for these providers ranged from 1.73 to 4.33 (mean 2. 83, standard deviation 0.48). Adjusted incidence rate ratios for domain and composite scale from the Poisson multiple regression are shown in Table 2; this model adjusted for provider gender, practice geography, experience level, and primary hospital's NTSV rate (exclusive of provider's contribution to this rate). The composite attitudes scale had an incident rate ratio of 1.21 (95\% CI 1.002-1.45, $p=0.048$ ), indicating that, for every 1 point increase in a provider's score on the composite scale, their NTSV cesarean rate decreased relatively by $21 \%$. For individual domains, attitudes towards the perceived benefits of cesarean and fear of vaginal birth approached significance [respectively, 1.07 (95\% CI 0.99-1.17) and 1.08 (95\% CI 0.99-1.17)]. (Table 2).

When dichotomizing providers by the Healthy People 2020 NTSV cesarean goal cut-off of $23.9 \%$, our sample reflected the overall California distribution, with $35 \%$ of providers meeting this goal and $65 \%$ of providers whose rate exceeded the goal. Providers meeting the HP2020 goal held attitudes more favorable toward vaginal birth compared with those over the HP2020 goal [adjusted mean 2.70 (95\% CI $2.58-2.83$ ) versus 2.91 (95\% CI 2.82-3.00), $p<0.01]$.

\section{Discussion}

We found a significant association between providers' attitudes and beliefs about birth to their own NTSV cesarean rate. This study was consistent with the findings of the original Canadian survey validation study [16], finding that California providers' attitudes towards birth were primarily divided along disciplinary lines. One of the most surprising findings in the disciplinary analysis was the wide range of obstetricians' attitudes, spanning views more pro-cesarean than maternal-fetal medicine providers all the way to those consistent with midwives. This large variation within a single discipline suggests that there may be key acculturation differences in obstetric training and practice environment, where a provider's attitudes and beliefs are influenced.

We took prior work an important step further by connecting provider attitudes to their own measured clinical outcomes. For providers with cesarean privileges, those meeting the Healthy People 2020 goal held attitudes that were more favorable toward vaginal birth than those not meeting this goal. In our regression analysis, as attitudes became more favorable toward cesarean and less favorable toward vaginal birth, a provider's NTSV cesarean rate increased proportionately. Additionally, we used a novel adjustor to account for local hospital culture - the primary hospital's NTSV cesarean rate less the provider's contribution to that rate. This adjustment highlights the 
a

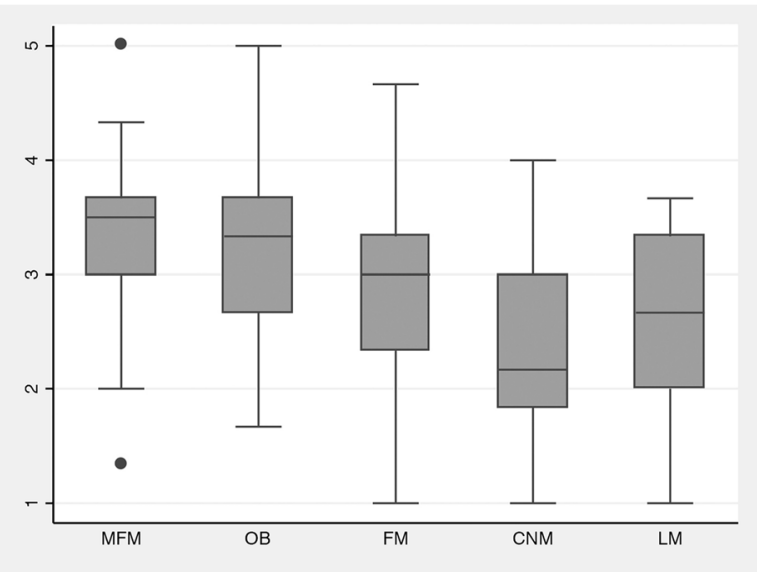

C

Domain 3: Fear of Vaginal Birth

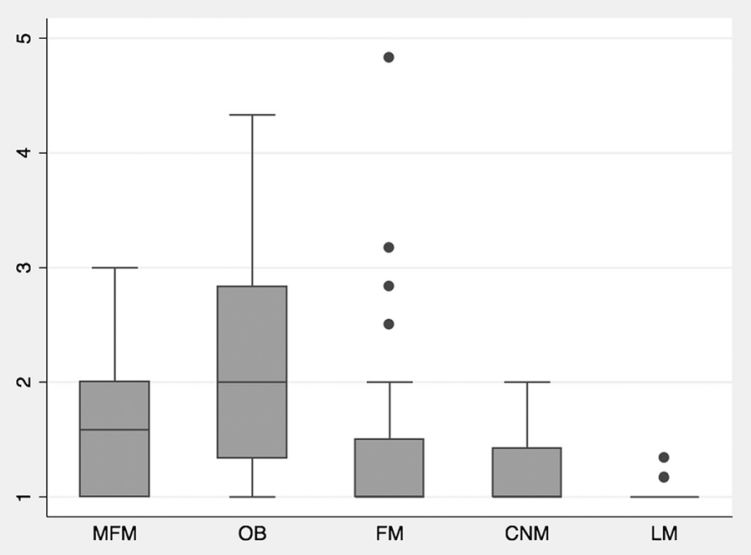

e

Domain 5: Maternal Role in Birth

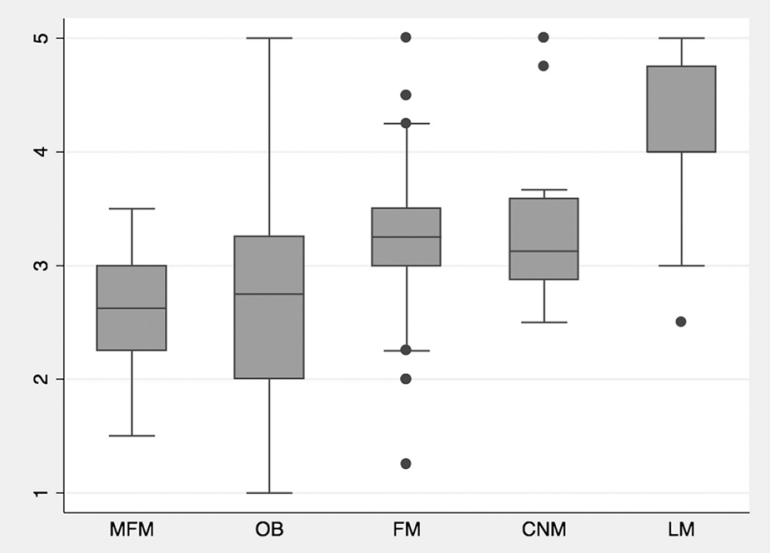

b

Domain 2: Benefits of Cesarean Section

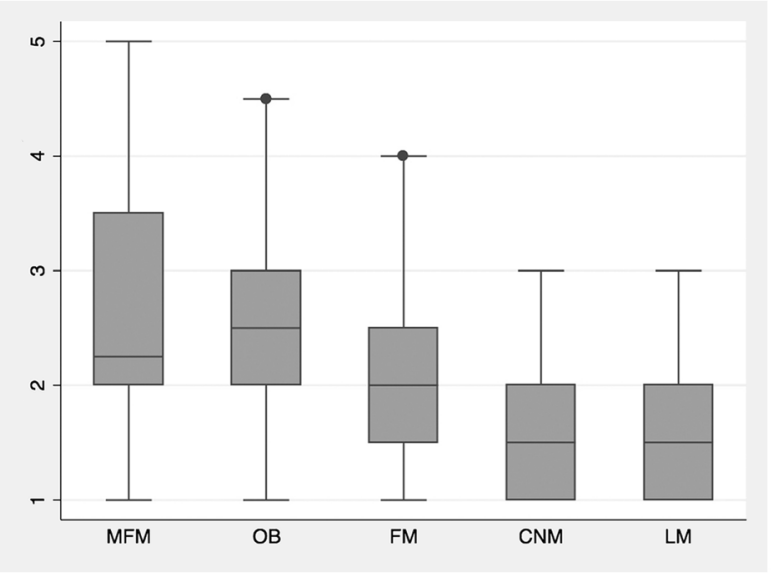

d Domain 4: Measures to Decrease the Cesarean Section Rate
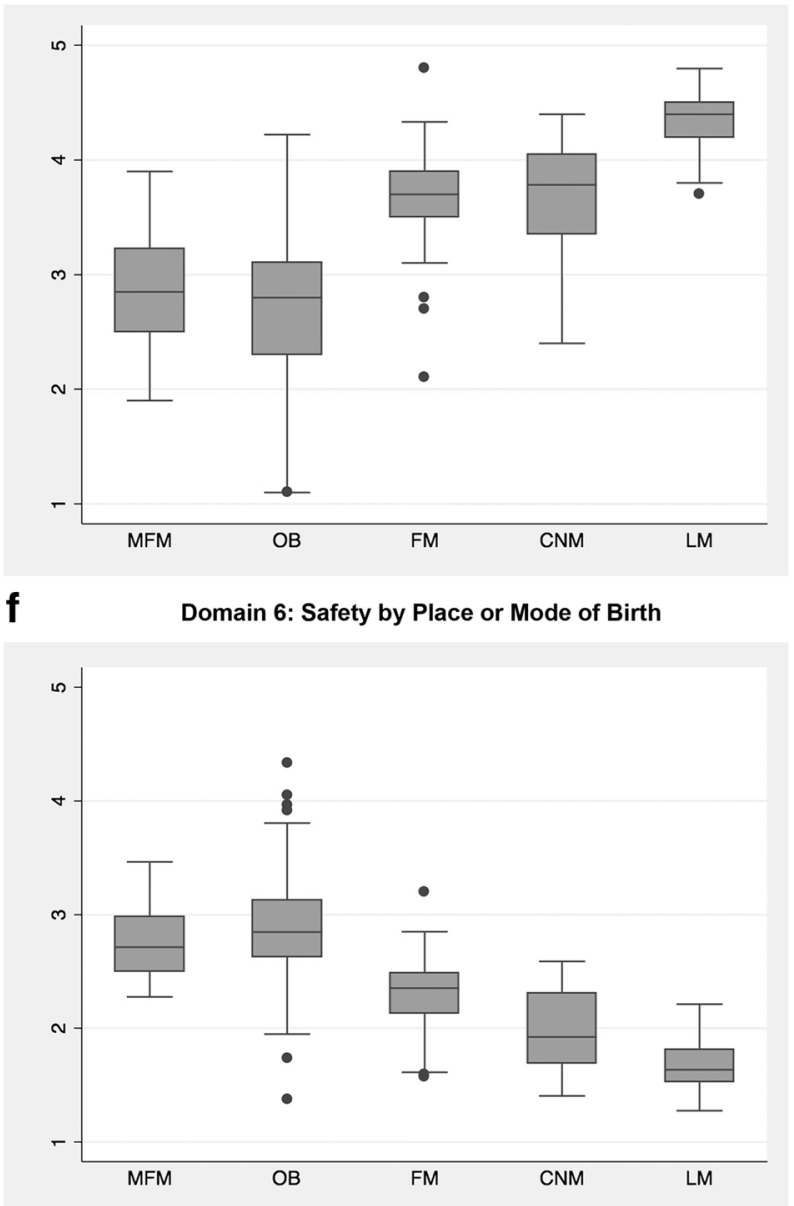

Fig. 2 a-f Boxplots of Provider Attitudes Scores on the Individual Domain Scales by Provider Discipline. Figure 2 a-f includes individual boxplots of providers' mean attitude scores for each individual attitudinal domain categorized by provider membership in a training discipline. Abbreviations: MFM: maternal fetal medicine; OB: obstetricians; family medicine: family medicine physicians; CNM: certified nurse midwives; LM: licensed midwives 
Table 2 Adjusted ${ }^{\mathrm{a}}$ Associations between Attitude Scores and Provider NTSV CS Rate ${ }^{\mathrm{b}}$

\begin{tabular}{|c|c|c|c|}
\hline Domain & Incidence Rate Ratio ${ }^{c}$ & $95 \% \mathrm{Cl}$ & $p$-value \\
\hline Fetal Monitoring & 1.01 & $0.94-1.10$ & 0.71 \\
\hline Benefits of CS & 1.07 & $0.99-1.17$ & 0.10 \\
\hline Fear of Vaginal Birth & 1.08 & $0.99-1.17$ & 0.09 \\
\hline Measures to Decrease $\mathrm{CS}^{\mathrm{d}}$ & 0.91 & $0.77-1.08$ & 0.28 \\
\hline Maternal Role in Birth ${ }^{d}$ & 0.93 & $0.85-1.02$ & 0.14 \\
\hline Safety by Place or Mode of Birth & 1.12 & $0.97-1.30$ & 0.14 \\
\hline Composite Scale & 1.21 & $1.002-1.45$ & 0.048 \\
\hline
\end{tabular}

Abbreviations: NTSV CS nulliparous, term, singleton, vertex cesarean section, CS cesarean section, Cl confidence interval

${ }^{a}$ Results are from individual Poisson regression models of the NTSV cesarean outcome, with one model for each row, with that variable the focal predictor and with additional covariates used to adjust for gender, experience level, geographic location of practice, primary hospital's NTSV cesarean rate calculated without the individual provider's contribution

${ }^{b}$ Only includes providers with confirmed privileges to perform cesarean sections who had at least 20 NTSV births over the two-year study period of 2013-2014

${ }^{c}$ Higher scores indicate attitudes more favorable toward cesarean section except for the two reverse-coded scales (as below)

dHigher scores indicate attitudes more favorable toward vaginal birth on these scales

impact of individual provider attitudes on top of that of local hospital norms and practices. These findings suggest that a provider's underlying attitudes, values, and beliefs play an important role in intrapartum decisions that ultimately affect birth outcomes.

Our results are consistent with, and provide a possible underlying mechanism for, other studies that have found provider differences such as demographics, litigation history, and practice environment are associated with provider self-report personal thresholds to perform cesareans $[22,23]$. By independently measuring attitudes while protecting the confidentiality of providers and using administrative data to associate attitudes with an unbiased measure of the individual provider-level cesarean rate, our study minimized social desirability bias, which can confound self-report data.

Of note, the actual magnitude of the point estimate of the association between composite attitudinal score and NTSV cesarean rate is quite large. For every 1 point increase in agreement with attitudes favoring cesarean, NTSV cesarean rates increased by a relative $21 \%$. For a provider with a baseline rate of $25 \%$, this would translate into an absolute change of $5.25 \%$. In comparison, the QUARISMA trial found changes to the absolute cesarean rate of $0.7-2.3 \%$ resulting from an audit and feedback mechanism in conjunction with hospital-based best practices implementation [24]. Targeting attitudinal change, which is a "bottom-up" method, in conjunction with quality improvement, or "top-down", efforts may enhance the impact of interventions. Research is needed to identify effective interventions to enhance evidencebased attitudes towards vaginal birth.

Training may offer a promising target for influencing attitudes that favor vaginal birth. One study found that providers who trained in hospitals with lower obstetric complication rates continued to have lower complication rates once in practice [25]. Most recently, one hospital program significantly decreased their primary cesarean rate by providing senior obstetric supervision of residents on labor and delivery, highlighting the impact of preceptor experience level on trainees [26]. The impact of integrating midwives into traditional obstetric training has been posited but not yet rigorously tested against clinical outcomes [27]. Finally, ongoing training and support after experiencing a traumatic delivery event may mitigate some of the fear attitudes associated with increased cesarean rate, which appear to impact entire hospital units and not just the providers involved. This was described recently in a study of unplanned hospital cesarean rates, which increased and stayed elevated for 4 weeks after any catastrophic neonatal outcome within that hospital [28].

\section{Limitations}

This cross-sectional study cannot draw conclusions regarding causality or time course between independent and dependent variables. Additionally, our a priori sample size justification assumed a linear regression analysis, but we found that a Poisson regression analysis was better suited to the outcome distribution. Thus, in order to assess the adequacy of the realized sample size for the reported effect sizes, one should consider the range of values included within the 95\% CI [29]. Where the null value was included along with values that would be clinically meaningful, one could conclude that the effect is ambiguous and would require a more precise estimate in future work. For example, we would assert that a $15 \%$ relative increase in the NTSV cesarean rate would be particularly clinically meaningful. When examining the 95\% CI for the effect size of the individual attitude items, we find that all of them included the null value (i.e. were not statistically significant) but three of them extended beyond an IRR of 1.15, suggesting that the results for those items are ambiguous and could warrant a study with 
a larger sample size. For the composite attitude measure, we found statistically significant and clinically significant effects.

Finally, the administrative data used to assess providerlevel cesarean rate was restricted to the provider listed on the birth certificate and subject to errors of attribution. For example, the provider listed as "Delivering Clinician" on the Birth Certificate is usually but not always the person that managed the majority of a patient's labor or made the decision to go to cesarean. Unfortunately, this method discounts information about providers who do not carry cesarean privileges but may play a major role in intrapartum care, and may be key decision-makers along the route that ends in either cesarean or vaginal delivery. For example, a provider may decide to admit a patient prior to the onset of active labor or use continuous electronic fetal monitoring despite a patient's low-risk status, both of which increase the likelihood of that patient requiring a cesarean, yet the cesarean birth would be attributed to the clinician who performed the surgery itself and not the provider managing the labor. Further studies are needed to assess the interplay of personnel on labor and delivery wards, how key decisions are made and birth outcomes attributed.

\section{Conclusions}

This is the first study we are aware of linking provider attitudinal differences to differences in measured birth outcomes. We found that the more providers' birth attitudes favored cesarean, the higher their NTSV cesarean rate. In contrast to earlier studies that have focused on physician demographics or litigation history, which are rarely modifiable without major policy changes, we sought to evaluate the influence of a modifiable attribute - a provider's personal attitudes and beliefs. These findings suggest further scrutiny is needed of how future providers are acculturated during training and while in practice, and how practice groups, hospital units, and inter-professional interactions may modify these attitudes to ultimately improve quality of care and health outcomes.

\section{Abbreviations \\ CMDC: California Maternal Data Center; CNM: Certified nurse midwives; family Medicine: Family medicine; family medicine-CS: Family medicine physicians with privileges to perform cesarean; HP2020: Healthy People 2020; LM: California licensed midwives; MFM: Maternal-fetal medicine; \\ NICU: Neonatal intensive care unit; NTSV: Nulliparous, term, singleton, vertex; OB: Obstetrician}

\section{Acknowledgements \\ Jairo Chavez, supported by the Ambulatory Primary Care Innovations Group of the NorthShore University HealthSystem Research Institute assisted in the preparation of this manuscript. Suzanne Eidson-Ton, MD, supported by the University of California Davis Department of Family and Community Medicine, contributed content expertise and assisted with pilot work for this study.}

\section{Funding}

This work was supported by grant number T32HS022236 from the Agency for Healthcare Research and Quality and grant number S-D936808-MCPAB from the University of California Davis Department of Family and Community
Medicine Jump Start Fund. Neither funding body had any role in the design, collection, analysis, interpretation of data, or in writing the manuscript.

\section{Availability of data and materials}

The data that support the findings of this study are available from the California Maternal Data Center, but restrictions apply to the availability of these data, which were used under license for the current study, and so are not publicly available. Data are however available from the authors upon reasonable request and with permission of the California Maternal Data Center.

\section{Authors' contributions}

EWV and JM designed the study with statistical consultation from DT and content area expertise from EM. EM created the provider data file for sampling and supplied outcomes data for participants. EWV and DT analyzed and interpreted the attitudinal and outcomes data. EWV wrote the majority of the manuscript with major contributions from all authors. All authors read and approved the final manuscript.

\section{Ethics approval and consent to participate}

This study was approved under expedited review by the University of California Davis Internal Review Board. Participants received the consent document, but signed consent was waived by the IRB.

\section{Competing interests}

The authors declare that they have no competing interests.

\section{Publisher's Note}

Springer Nature remains neutral with regard to jurisdictional claims in published maps and institutional affiliations.

\section{Author details}

${ }^{1}$ Department of Family Medicine, The University of Chicago, Pritzker School of Medicine, NorthShore University HealthSystem Research Institute, 1001 University Place, Evanston, IL 60201, USA. ²Department of Obstetrics and Gynecology, The University of Chicago, Pritzker School of Medicine, NorthShore University HealthSystem Research Institute, 1001 University Place, Evanston, IL 60201, USA. ${ }^{3}$ California Maternal Quality Care Collaborative, Stanford University, Stanford Medical School Office Building, 1265 Welch Road, MS 5415, Stanford, CA 94305, USA. ${ }^{4}$ Center for Healthcare Policy and Research and Department of Pediatrics, University of California Davis School of Medicine, 2103 Stockton Blvd, Sacramento, CA 95817, USA. ${ }^{5}$ Center for Healthcare Policy and Research and Department of Family and Community Medicine, University of California Davis School of Medicine, 2103 Stockton Blvd, Sacramento, CA 95817, USA.

Received: 28 July 2017 Accepted: 19 April 2018

Published online: 29 May 2018

\section{References}

1. Caughey AB, Cahill AG, Guise JM, Rouse DJ. Safe prevention of the primary cesarean delivery. Am J Obstet Gynecol. 2014;210:179-93.

2. Childbirth Connection. Vaginal or cesarean Birth. What is at stake for women and babies. New York: Childbirth Connection; 2012. p. 52.

3. Berg CJ, Atrash HK, Koonin LM, Tucker M. Pregnancy-related mortality in the United States, 1987-1990. Obstet Gynecol. 1996;88:161-7.

4. Berg CJ, Callaghan WM, Syverson C, Henderson Z. Pregnancy-related mortality in the United States, 1998 to 2005. Obstet Gynecol. 2010;116: 1302-9.

5. Berg CJ, Chang J, Callaghan WM, Whitehead SJ. Pregnancy-related mortality in the United States, 1991-1997. Obstet Gynecol. 2003;101:289-96.

6. Office of Disease Prevention and Health Promotion. Healthy people 2020: maternal, infant, and child health. Washington (DC), 2016. Retrieved from https://www.healthypeople.gov/2020/topics-objectives/ topic/maternal-infant-and-child-health/objectives. Accessed 22 Nov 2016.

7. National Quality Forum (NQF). National Voluntary Consensus Standards for perinatal care 2008: a consensus report. Washington, DC: NQF; 2009. Retrieved from https://www.qualityforum.org/Publications/2009/05/ National_Voluntary_Consensus_Standards_for_Perinatal_Care_2008.aspx. Accessed 22 Nov 2016.

8. Main EK, Moore D, Farrell B, Schimmel LD, Altman RJ, Abrahams C, et al. Is there a useful cesarean birth measure? Assessment of the nulliparous term 
singleton vertex cesarean birth rate as a tool for obstetric quality improvement, Am J Obstet Gynecol. 2006:194:1644-51. discussion 51-2

9. Kozhimannil KB, Law MR, Virnig BA. Cesarean delivery rates vary tenfold among US hospitals; reducing variation may address quality and cost issues. Health Aff (Millwood). 2013;32:527-35.

10. Caceres IA, Arcaya M, Declerca E, Belanoff CM, Janakiraman V, Cohen B, et al. Hospital differences in cesarean deliveries in Massachusetts (US) 20042006: the case against case-mix artifact. PLoS One. 2013;8:e57817.

11. Metz TD, Allshouse AA, Gilbert SA, Doyle R, Tong A, Carey JC. Variation in primary cesarean delivery rates by individual physician within a singlehospital laborist model. Am J Obstet Gynecol. 2016;214:531 e1-6.

12. Main EK, Morton CH, Melsop K, Hopkins D, Giuliani G, Gould JB. Creating a public agenda for maternity safety and quality in cesarean delivery. Obstet Gynecol. 2012;120:1194-8.

13. Committee Opinion No. 687: approaches to limit intervention during labor and birth. Obstet Gynecol. 2017;129:e20-e8.

14. Olatunbosun OA, Edouard L, Pierson RA. Physicians' attitudes toward evidence based obstetric practice: a questionnaire survey. BMJ. 1998;316:365-6.

15. Reime B, Klein MC, Kelly A, Duxbury N, Saxell L, Liston R, et al. Do maternity care provider groups have different attitudes towards birth? BJOG. 2004;111:1388-93.

16. Klein MC, Kaczorowski J, Hall WA, Fraser W, Liston RM, Eftekhary S, et al. The attitudes of Canadian maternity care practitioners towards labour and birth: many differences but important similarities. J Obstet Gynaecol Can. 2009:31:827-40.

17. Burns $L R$, Geller $S E$, Wholey DR. The effect of physician factors on the cesarean section decision. Med Care. 1995;33:365-82.

18. Mitler LK, Rizzo JA, Horwitz SM. Physician gender and cesarean sections. J Clin Epidemiol. 2000;53:1030-5.

19. Tussing AD, Wojtowycz MA. The effect of physician characteristics on clinical behavior: cesarean section in New York state. Soc Sci Med. 1993;37:1251-60.

20. State of California, Office of Statewide Health Planning and Development, Healthcare Workforce Development Division. Medical service study areas. Sacramento: Office of Statewide Health Planning and Development; 2013. Retrieved from https:/www.oshpd.ca.gov/HWDD/CalPCO.html\#Maps-GIS. Accessed 21 Mar 2017

21. Dillman DA, Smyth JD, Christian LM, Dillman DA. Internet, mail, and mixed-mode surveys : the tailored design method. 3rd ed. Hoboken: Wiley \& Sons; 2009.

22. Cheng IW, Snowden JM, Handler S, Tager IB, Hubbard A, Caughey AB. Clinicians' practice environment is associated with a higher likelihood of recommending cesarean deliveries. J Matern Fetal Neonatal Med. 2014;27:1220-7.

23. Cheng YW, Snowden JM, Handler SJ, Tager IB, Hubbard AE, Caughey AB. Litigation in obstetrics: does defensive medicine contribute to increases in cesarean delivery? J Matern Fetal Neonatal Med. 2014;27:1668-75.

24. Chaillet N, Dumont A, Abrahamowicz M, Pasquier JC, Audibert F, Monnier P, et al. A cluster-randomized trial to reduce cesarean delivery rates in Quebec N Engl J Med. 2015;372:1710-21.

25. Asch DA, Nicholson S, Srinivas S, Herrin J, Epstein AJ. Evaluating obstetrical residency programs using patient outcomes. JAMA. 2009;302:1277-83.

26. Bardos J, Loudon H, Rekawek P, Friedman F, Brodman M, Fox NS. Association between senior obstetrician supervision of resident deliveries and mode of delivery. Obstet Gynecol. 2017;129:486-90.

27. King TL, Laros RK, Parer JT. Interprofessional collaborative practice in obstetrics and midwifery. Obstet Gynecol Clin N Am. 2012;39:411-22.

28. Dan O, Hochner-Celnikier D, Solnica A, Loewenstein Y. Association of Catastrophic Neonatal Outcomes with Increased Rate of subsequent cesarean deliveries. Obstet Gynecol. 2017;129:671-5.

29. Colegrave N, Ruxton G. Confidence intervals are a more useful complement to nonsignificant tests than are power calculations. Behav Ecol. 2003;14:446-7.

\section{Ready to submit your research? Choose BMC and benefit from:}

- fast, convenient online submission

- thorough peer review by experienced researchers in your field

- rapid publication on acceptance

- support for research data, including large and complex data types

- gold Open Access which fosters wider collaboration and increased citations

- maximum visibility for your research: over $100 \mathrm{M}$ website views per year

At BMC, research is always in progress.

Learn more biomedcentral.com/submissions 